\title{
A Numerical Analysis for Predicting the Thermal Conductivity of Carbon Nanotube Reinforced Copper-Matrix Nanocomposites
}

\author{
Iman Eslami Afrooz ${ }^{\mathrm{a}}$, Puteri Sri Melor Binti Megat Yusoff, Faiz Ahmad and Ali Samer Muhsan \\ Department of Mechanical Engineering, Universiti Teknologi PETRONAS, Malaysia
}

\begin{abstract}
Thermal conductivity of carbon nanotubes (CNTs) copper-matrix nanocomposites was predicted by using numerical approach. In the present study, twenty representative volume elements (RVEs) were modeled by assuming that the CNTs are distributed homogeneously in the copper $(\mathrm{Cu})$ matrix. It is assumed that each RVE contains different pattern of CNTs distribution while the direction, diameter and length of CNTs are held constant. The effect of the CNTs-matrix interfacial resistance was also negligible. Therefore, it was observed that the predicted values of thermal conductivity would reach to the upper-bound rule of mixtures.
\end{abstract}

\section{Introduction}

Having a Young's modulus of more than $1 \mathrm{TPa}$, estimated tensile strength of over $150 \mathrm{GPa}$, and thermal conductivity $\mathrm{K}$ up to $6000 \mathrm{~W} / \mathrm{mK}$ [1-4], CNTs are ideal reinforcement for advanced composites materials for various engineering applications such as aerospace, energy, oil and gas, medicine, automotive, and electronic devices. Over the last decade, numerous works have focused on the enhancement of the thermal conductivity for polymer matrix composites. While only limited work were conducted for metal matrix composites. Recently, due to the high thermal and electrical conductivity of $\mathrm{Cu}$ and its potential applications for various electronic devices, the interest in using $\mathrm{Cu}$ as a matrix in nanocomposite materials has increased. However, due to some difficulties such as achieving homogenous dispersion of CNTs within metal matrices especially at high CNTs loading and lack of suitable synthesis techniques $[5,6]$, research on metal-matrix composites has been to some extent limited. Maintaining a homogeneous distribution of CNTs in the matrix, loss of CNTs during processing, interfacial reactions and bonding with the matrix are some of the critical issues which have been the main concerns among scientists in the fabrication of CNTs metal-matrix nanocomposites [7, 8]. To overcome these challenges, different fabrication processes such as thermal spraying [9], hot pressing [10], hot extrusion [11] and spark plasma sintering (SPS) [12] have been proposed by researchers.

In spite of recent progress in improving the dispersion of CNTs in $\mathrm{Cu}$ matrix, the remarkable amount of agglomeration of CNTs at the $\mathrm{Cu}$ grain boundaries have also been reported [13, 14]. This

\footnotetext{
${ }^{\text {a }}$ Corresponding author : author@e-mail.org
}

This is an Open Access article distributed under the terms of the Creative Commons Attribution License 2.0, which permits unrestricted use, distribution, and reproduction in any medium, provided the original work is properly cited. 
defect has a direct impact on the properties of such nanocomposites which results in lower thermal conductivity than expected. A novel processing technique has recently been proposed by Chu et al. [15] to fabricate $\mathrm{CNT} / \mathrm{Cu}$ nanocomposites. It used the particles-compositing method to distribute CNTs uniformly in the $\mathrm{Cu}$ matrix. Using this technique, the agglomerated $\mathrm{CNT}$ ropes or lumps have been disintegrated into the individual CNTs. Although a good dispersion was reported, the enhancement in the thermal conductivity of fabricated CNTs/Cu composites was not measured.

Kim et al. [16] investigated the thermal conductivity of CNTs reinforced $\mathrm{Cu}$ matrix nanocomposites synthesized via the molecular-level mixing process followed by SPS. They found that the thermal conductivity of $\mathrm{CNTs} / \mathrm{Cu}$ nanocomposites are lower than that of unreinforced $\mathrm{Cu}$ and is decreased by increasing the CNT volume fraction. The interfacial resistance between CNT and $\mathrm{Cu}$ has been reported as a reason of this property deterioration. The better enhancement in the value of $\mathrm{K}$ was reported by $\mathrm{Cho}$ et al. [17]. They studied the thermal conductivity of $\mathrm{CNTs} / \mathrm{Cu}$ nanocomposites fabricated by using hetero-aggregation method based on a wet mixing process followed by SPS. They reported higher thermal conductivities for $\mathrm{CNT} / \mathrm{Cu}$ nanocomposites than that of unreinforced $\mathrm{Cu}$ up to $3 \% \mathrm{CNT}$ volume fraction. However, a descending trend was reported for the values of $\mathrm{K}$ after reaching a pike of $359.2 \mathrm{~W} / \mathrm{m} . \mathrm{K}$ for the $1 \% \mathrm{CNT}$ volume fraction. The thermal conductivity values even lower than that of unreinforced $\mathrm{Cu}$ were also reported for about $5 \%$ and $10 \%$ of $\mathrm{CNT}$ volume fractions.

Several factors were reported as the cause of the loss in the overall thermal conductivity of the composites such as interface thermal resistance, porosities, inhomogeneous distribution and incomplete consolidation [10-14]. As it has been mentioned in the literature, the thermal conductivity of composites materials are highly influenced by the distribution factor. That is to say, the more uniform and homogeneous CNTs dispersion are, the higher thermal properties would be achieved. Besides, CNT has ultra-high conductivity along the tube direction. Therefore, the thermal conductivity of the composites could be greatly improved when reinforced by the unidirectional CNT fibers. The purpose of this research is to predict the thermal conductivity of $\mathrm{CNT} / \mathrm{Cu}$ nanocomposites using numerical analysis which has never been reported in the literature to the best knowledge of the author. For this purpose, several models of $\mathrm{Cu}$-matrices reinforced with $\mathrm{CNT}$ fibers have been simulated based on the following assumptions:

- CNT fibers were being distributed homogeneously and unidirectionally in which all tubes were arranged along a heat transfer direction.

- The fiber-matrix interface thermal resistance is negligible.

\section{Finite-Element Numerical Approach}

In the present study, the same as in our previous work [18], 3-dimensional (3D) finite element modelling was carried out using the commercial MSC.Marc software to evaluate thermal conductivity of CNT/Cu nanocomposites. The representative volume elements (RVEs) considered for this study is shown in Fig 1. The RVE has a dimension of $60 \times 60 \times 300 \mathrm{~nm} 3$ filled with copper as the matrix material having sintered thermal conductivity of $330 \mathrm{~W} / \mathrm{m} . \mathrm{K}$. Subsequently, the RVE was meshed and divided into the smaller elements and nodes which were used later as places for CNTs distribution. CNTs considered in this study have a length, diameter and thermal conductivity of $50 \mathrm{~nm}, 1.4 \mathrm{~nm}$ and $3000 \mathrm{~W} / \mathrm{m} . \mathrm{K}$ respectively. In total, twenty RVEs have been categorized into four different groups based on the CNT volume fractions with each of the distinct group having a peculiar CNT arrangement. The kind of CNTs arrangement was determined by the number of nodes in the RVE. This meant that the number of possible places that could be occupied by CNTs increase as the number of nodes in the RVE increased. A Matlab program has been developed to create the random distribution of CNTs inside the RVE. 


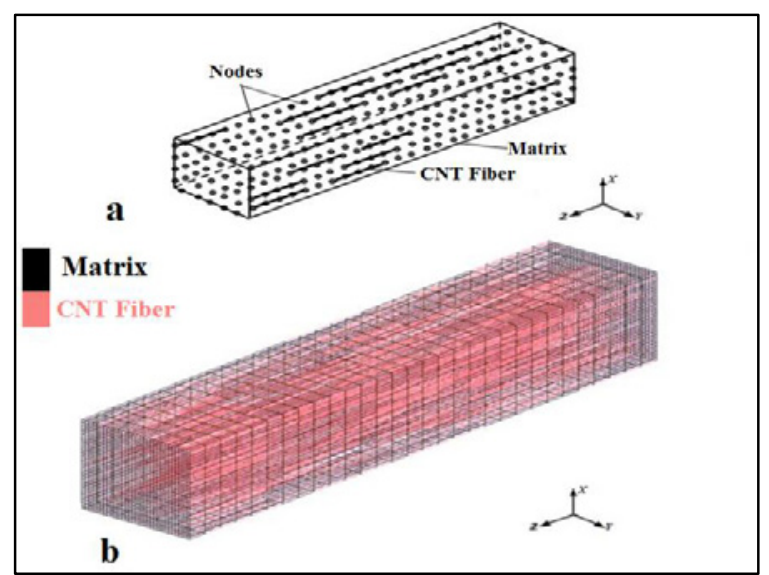

Fig. 1. a. Schematic representation of the RVE model. b. Nanocomposite model containing 2000 unidirectional CNT fibers (volume fraction $=10 \%$ ).

In the evaluation of thermal conductivity, a temperature difference $\Delta \mathrm{T}$ of $10^{\circ} \mathrm{C}$ was applied to the RVEs along the $\mathrm{Z}$ direction to obtain the heat flux $\mathrm{q}$. The thermal conductivity of CNT reinforced composites K was then calculated using Fourier's law Eq. 1.

$$
q=k \frac{\Delta T}{\Delta X}
$$

\section{Results and Discussion}

The predicted thermal conductivity of $\mathrm{CNT} / \mathrm{Cu}$ nanocomposites is given in Table 1 . As shown in Table 1, different values of thermal conductivity were obtained for every constant CNT volume fraction. That is to say that thermal conductivity of nanocomposites is highly influenced by the variety of types of CNTs' distribution (arrangement) inside the matrix even when the orientations and the volume fractions of the CNTs are considered constant. This proves that there is an influence of the distribution of CNTs on the thermal conductivity of nanocomposites. These data also platted in Fig. 2 with comparison to Rule of Mixture and previous work by Chu et al. [15].

Table 1. Thermal conductivities of RVEs for various volume fractions.

\begin{tabular}{|c|c|c|c|c|c|c|}
\hline \multirow{2}{*}{\multicolumn{2}{|c|}{ Arrangement }} & \multicolumn{5}{|c|}{ CNT Volume Fraction [\%] } \\
\hline & & 0 & 2 & 5 & 7.5 & 10 \\
\hline \multirow{5}{*}{$\begin{array}{c}\text { Thermal } \\
\text { Conductivity } \\
{[\mathrm{W} / \mathrm{m} \cdot \mathrm{K}]}\end{array}$} & 1 & 330 & 380.8 & 452.2 & 516.99 & 575.1 \\
\hline & 2 & 330 & 379.8 & 451.3 & 515.28 & 571.2 \\
\hline & 3 & 330 & 379.1 & 449.9 & 507.55 & 561.3 \\
\hline & 4 & 330 & 375.9 & 440.2 & 505.7 & 561.3 \\
\hline & 5 & 330 & 369.7 & 427.8 & 461.71 & 505.4 \\
\hline
\end{tabular}

It is shown in Fig. 2 that the thermal conductivity of $\mathrm{CNT} / \mathrm{Cu}$ nanocomposites increases with increasing CNT volume fraction. It is clearly seen that our predicted values without considering the effects of interface thermal resistance and agglomeration of CNTs yielded higher values of K than that 
of the experimental data. However, it could be deduced that the underperformance of the experimental values can be related to the unfavourable factors such as interfacial resistance between the $\mathrm{Cu}$ matrix and CNT reinforcement, porosity and inhomogeneous distribution of CNTs [15].

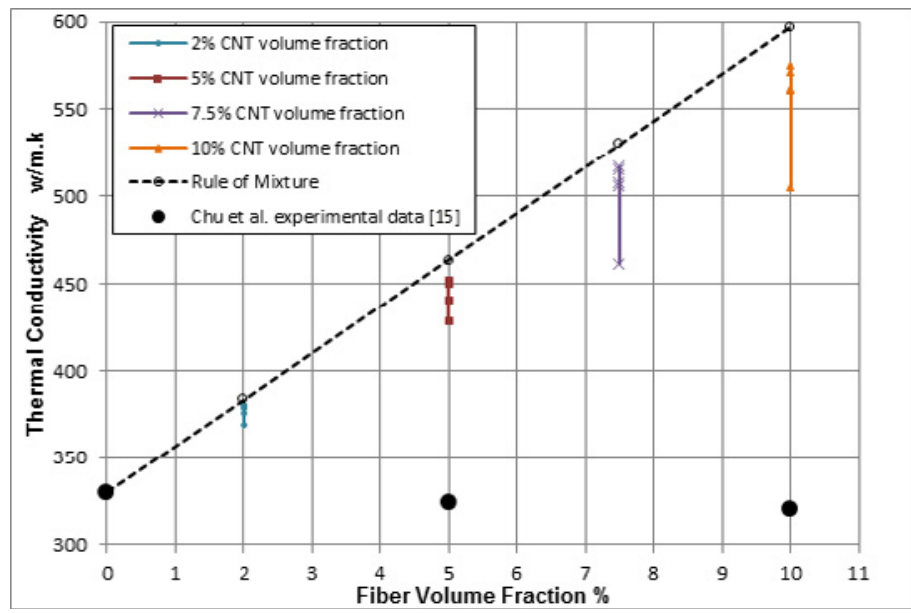

Fig. 2. Thermal conductivity of $\mathrm{CNT} / \mathrm{Cu}$ nanocomposites versus $\mathrm{CNT}$ volume fraction.

\section{Conclusion}

In summary, 3D finite element models of $\mathrm{CNT} / \mathrm{Cu}$ nanocomposites were developed and simulated using the commercial MSC. Marc software. Subsequently, the thermal conductivity of the nanocomposite models was predicted where enhancement in thermal conductivity compared to the unreinforced matrix was observed. It should be noted that the distribution of CNTs in the metal matrix played an important role in determining the thermal conductivity of nanocomposites, even when CNTs orientation and volume fraction were constant. Therefore, there were two requirements for achieving high thermal conductivity namely homogeneous dispersion of CNTs inside the matrix with less agglomeration and extremely low thermal resistance between CNTs and matrix. For that reason, more work needed to be done in the case of improving thermal properties of nanocomposites.

\section{References}

1. A.M.K. Esawi, M. M. Farag, Carbon nanotube reinforced composites: potential and current challenges, Materials \& Design. 28, 2394-2401(2007).

2. S. Iijima, Helical microtubules of graphitic carbon, Nature. 354, 56-58 (1991).

3. T.T. Erik, Z. Ren, T.W. Chou, Advances in the science and technology of carbon nanotubes and their composites: a review, Compos. Sci. Technol. 61, 1899-912 (2001).

4. R.H. Baughman, A.A. Zakhidov, W.A. de Heer, Carbon nanotubes: the route toward applications. Science. 297, 787-92 (2000).

5. A. S. Muhsan, F. Ahmad, N. M. Mohamed, and M. R. Raza, Nanoscale dispersion of carbon nanotubes in copper matrix nanocomposites for thermal management applications, Journal of Nanoengineering and Nanomanufacturing. 3, 248-252 (2013). 
6. A. S. Muhsan, F. Ahmad, N. M. Mohamed, and M. R. Raza, Uniform dispersion of multiwalled carbon nanotubes in copper matrix nanocomposites using metal injection molding technique, International Journal of Manufacturing Engineering (2013).

7. A. S. Muhsan, F. Ahmad, N. M. Mohamed, and M. R. Raza, Fabrication and microstructural analysis of CNTs reinforced copper matrix nanocomposites via MIM technique, Applied Mechanics and Materials. 459, 11-17 (2014).

8. A. Bhat, V.K. Balla, S. Bysakh, D. Basu, S. Bose, A. Bandyopadhyay, Carbon nanotube reinforced $\mathrm{Cu}-10 \mathrm{Sn}$ alloy composites: mechanical and thermal properties, Materials Science and Engineering. 528, 6727-6732 (2011).

9. T. Laha, A. Agarwal, T. McKechnie, S. Seal, Synthesis and characterization of plasma spray formed carbon nanotube reinforced aluminum composite, Materials Science and Engineering: A. 381, 249-258 (2004).

10. C. Kim, B. Lim, B. Kim, U. Shim, S. Oh, B. Sung, et al., Strengthening of copper matrix composites by nickel-coated single-walled carbon nanotube reinforcements, Synthetic Metals. 159, 424-429 (2009).

11. C.F. Deng, D.Z. Wang, X.X. Zhang, A.B. Li, Processing and properties of carbon nanotubes reinforced aluminum composites, Materials Science and Engineering A. 444, 138-145 (2007).

12. H. Kwon, M. Estili, K. Takagi, T. Miyazaki, A. Kawasaki, Combination of hot extrusion and spark plasma sintering for producing carbon nanotube reinforced aluminum matrix composites, Carbon. 47, 570-577 (2009).

13. W.M. Daoush, B.K. Lim, C.B. Mo, D.H. Nam, S.H. Hong, Electrical and mechanical properties of carbon nanotube reinforced copper nanocomposites fabricated by electroless deposition process, Materials Science and Engineering: A. 513-514 247-253 (2009).

14. S.M. Uddin, T. Mahmud, C. Wolf, C. Glanz, I. Kolaric, C. Volkmer, et al., Effect of size and shape of metal particles to improve hardness and electrical properties of carbon nanotube reinforced copper and copper alloy composites, Composites Science and Technology. 70, 2253-2257 (2010).

15. K. Chu, Q. Wu, C. Jia, X. Liang, J. Nie, W. Tian, G. Gai, H. Guo, Fabrication and effective thermal conductivity of multi-walled carbon nanotubes reinforced $\mathrm{Cu}$ matrix composites for heat sink applications, Composites Science and Technology. 70, 298-304 (2010).

16. K.T. Kim, J. Eckert, G. Liu, J.M. Park, B.K. Lim, S.H. Hong, Influence of embedded-carbon nanotubes on the thermal properties of copper matrix nanocomposites processed by molecular-level mixing, Scripta Materialia. 64, 181-184 (2011).

17. S. Cho, K. Kikuchi, T. Miyazaki, K. Takagi, A. Kawasaki, T. Tsukada, Multiwalled carbon nanotubes as a contributing reinforcement phase for the improvement of thermal conductivity in copper matrix composites, Scripta Materialia. 63, 375-378 (2010).

18. I.E. Afrooz, A. Öchsner, M. Rahmandoust, Effects of the carbon nanotube distribution on the macroscopic stiffness of composite materials, Computational Materials Science. 51, 422-429 (2012). 